\title{
The Eye of the Beholder. Reconsidering the Notions of Pro-Poor Growth and Progressivity, with an Application to Vietnam
}

\author{
Guido Erreygers" ${ }^{*} \&$ and Bui Thi Kim Thanh*
}

* Department of Economics, University of Antwerp; ${ }^{\S}$ Centre for Health Policy, University of Melbourne, Australia

Correspondence details: Guido Erreygers, Department of Economics, University of Antwerp, Prinsstraat 13, 2000 Antwerpen, Belgium, Tel. +32-3-265 40 52, guido.erreygers@uantwerpen.be, https://orcid.org/0000-0002-4512-9567 (corresponding author); BuiThi Kim Thanh, Department of Economics, University of Antwerp, Prinsstraat 13, 2000 Antwerpen, Belgium, X.BuiThiKimThanh@student.uantwerpen.be

Notes on contributors: Guido Erreygers is Professor of Economics at the University of Antwerp and Visiting Researcher at the University of Melbourne; Bui Thi Kim Thanh is PhD researcher at the University of Antwerp.

Acknowledgements: We are grateful to Paul Glewwe for his advice with regard to the Vietnamese survey data and to Philippe Van Kerm for the STATA routines to decompose the change of the Gini coefficient. The STATA code for the calculation of the decompositions presented in the paper can be obtained upon request from the authors. The paper has been presented at research seminars in the University of Antwerp and the University of Louvain in Brussels, and at Vietnam's Business \& Economics Research Conference 2018 in Ho Chi Minh City. We thank everyone who commented upon the paper, and especially the two reviewers of the journal whose comments and observations have been very helpful. All errors are our responsibility.

Conflicts of interest: None.

Word count: 7656 words

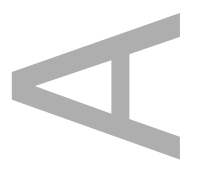

This is the author manuscript accepted for publication and has undergone full peer review but has not been through the copyediting, typesetting, pagination and proofreading process, which may lead to differences between this version and the Version of Record. Please cite this article as doi: $10.1111 /$ rode. 12576

This article is protected by copyright. All rights reserved 

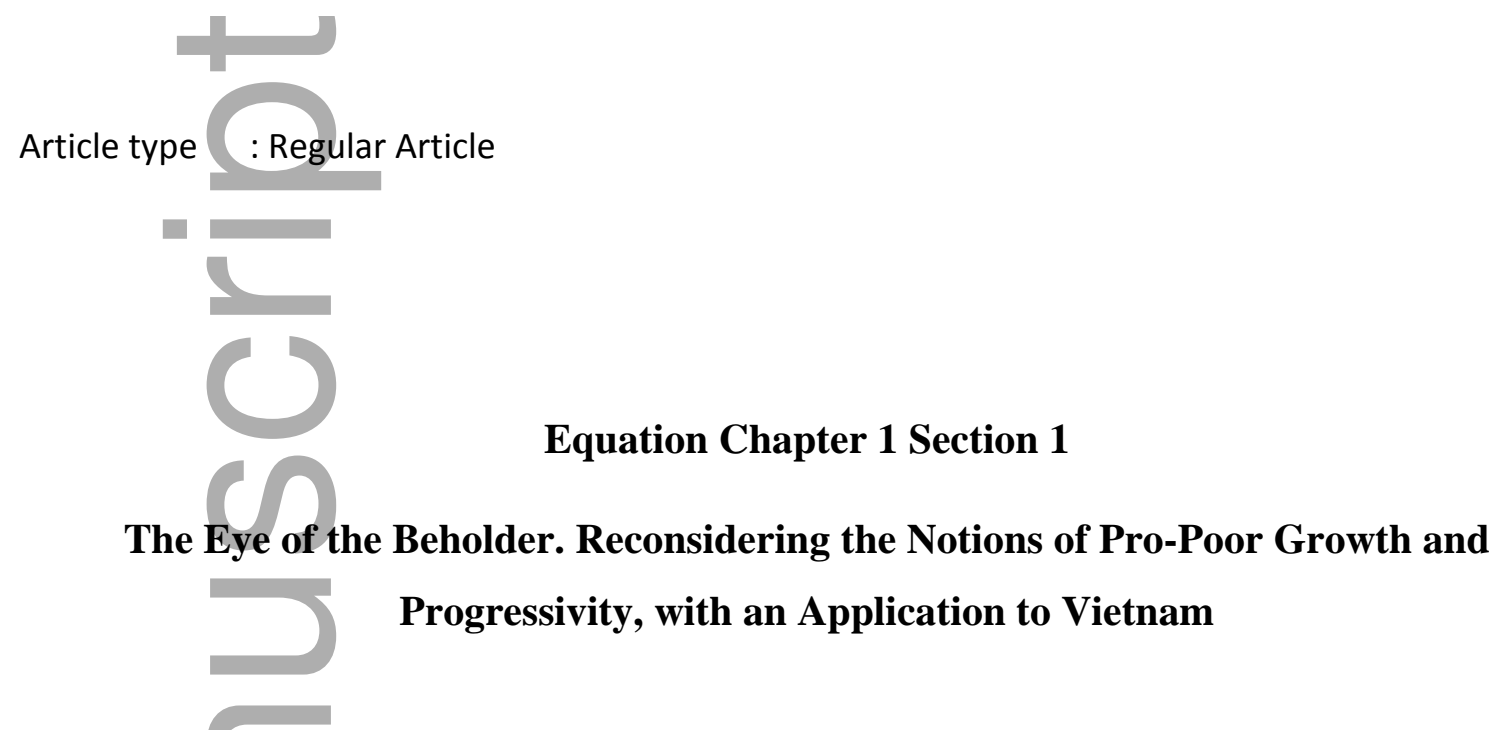

\begin{abstract}
Both policymakers and economists have tried to find criteria to assess whether economic growth is pro-poor. In this paper we reconsider the inequality-oriented approach of Jenkins and Van Kerm (2006). They look at the changes in the whole income distribution, and decompose the change in income inequality, measured by the Gini coefficient, into a progressivity and a re-ranking component. They define a pro-poor (or progressive) change as one where the changes in income are more to the benefit of those who are initially poor than to the benefit of those who are initially rich. We challenge this assumption, and maintain that also the point of view of the finally poor and the finally rich should be taken into account when evaluating whether growth is pro-poor. We suggest a new decomposition method, based on an inequality index of the Generalized Entropy family, which allows the change in income inequality to be decomposed exactly into a forward-looking and a backward-looking progressivity component. Our empirical illustration, using data from household surveys in Vietnam, shows that economic growth in Vietnam has been pro-poor from a forward-looking perspective, but not from a backward-looking perspective.
\end{abstract}

Keywords: income inequality, inequality evolution, pro-poor growth, inequality decomposition, Vietnam.

JEL classification codes: $\mathrm{I} 32, \mathrm{O} 11, \mathrm{O} 53$ 


\section{Introduction}

Both policymakers and economists have tried to find criteria to assess whether economic growth is pro-poor, or, more generally, whether it is 'inclusive'. Broadly speaking, two approaches have been followed, one focusing on the effects on poverty and another focusing on the effects on inequality. While the first examines whether the poor have benefited from economic growth (in the sense that the rate of poverty has decreased), the second explores whether the changes in income have been more to the benefit of the poor than to that of the rich. In both cases, it is customary to look at the issue from the perspective of a given 'base year'. A good example is provided by the following position: "The question often arises as to how the gains from aggregate economic growth (or the losses from contraction) were distributed across households according to their initial incomes or expenditures." (Ravallion and Chen, 2003: 93; emphasis added) This stance implies that if one wants to determine whether growth in Vietnam between 2000 and 2014 has been pro-poor, the focus should be on how the situation of the initially poor (i.e., those who were poor in the year 2000) and that of the initially rich has changed. We agree that this is a legitimate and maybe even natural point of view; but we challenge the (implicit) assumption that this is the only or exclusive point of view. As suggested by Grimm (2007) and Bourguignon (2011), we believe that also the point of view of the finally poor (in our example, those who are poor in the year 2014) and that of the finally rich should be taken into account when evaluating whether growth is pro-poor.

The issue is especially relevant for the inequality-oriented approach. In that literature, the decomposition of the change in inequality into a mobility and a progressivity component (Jenkins and Van Kerm, 2006) has been influential. The progressivity component is seen as an indicator of the pro-poor character of growth: "We show that when income inequality is measured using any member of the generalized Gini class of indices, the change in inequality between two points in time can be additively decomposed into two components, one summarizing mobility in the form of reranking, and one summarizing progressivity in income growth (i.e. whether income growth is pro-poor rather than pro-rich)." (Jenkins and Van Kerm, 2006: 532) In the present paper, we first argue that questions may be raised about the interpretation of this decomposition, and we then show that the use of a level-dependent rather than rank-dependent inequality index yields a much clearer insight into the progressivity of income growth.

We begin with a short overview of how pro-poor growth has been defined in recent years, and give a brief account of studies on inequality in Vietnam (Section 2). We then present and 
examine the methodological framework of Jenkins and Van Kerm (2006), and formulate an alternative approach (Section 3). For the empirical application of the decomposition methodology we need panel data. We construct three panels based on Vietnamese household survey data to explore the pro-poor character of economic growth in Vietnam (Section 4). We compare our results to those obtained in a previous study by Wagstaff (2009), give a graphical illustration of our progressivity concepts, and discuss the scope and limitations of the approach adopted in the paper (Section 5). We end with a few concluding remarks.

\section{Literature review}

\subsection{The definition and measurement of pro-poor growth}

Essentially, three different approaches have been adopted to arrive at a definition of pro-poor growth. The poverty-reducing approach defines growth as pro-poor if it ameliorates the position of the poor, regardless of whether the position of the non-poor ameliorates or deteriorates (Ravallion, 2004). Two things are needed to apply this method: a definition of the poverty line, in order to distinguish the poor from the non-poor, and a poverty index, in order to measure the change in the amount of poverty over a period of time. The two other approaches look at the whole population, not just at the poor, and compare the change in the situation of the poor to that of the non-poor (Kakwani and Pernia, 2000; Ravallion and Chen, 2003; Kakwani and Son, 2008). In the relative version, growth is defined as pro-poor if it is such that in relative terms the poor benefit more than the non-poor. The implication is that relative inequality decreases during periods of pro-poor growth. In the absolute version, there is pro-poor growth if the poor gain more than the non-poor in absolute terms. This leads to a decrease in absolute inequality.

Based on these definitions, several concepts have been introduced to measure whether growth is pro-poor or not. A non-exhaustive list includes the poverty bias of growth (McCulloch and Baulch, 1999), the poverty elasticity of growth (Kakwani and Pernia, 2000), the poverty growth curve (Son, 2003), the growth incidence curve (Ravallion and Chen, 2003), the absolute growth incidence curve (Grosse, Harttgen and Klasen, 2008), and the poverty equivalent growth rate (Kakwani and Son, 2008). Empirical studies with applications to Vietnam have been made by Fritzen (2002), Kakwani and Son (2004), Son and Kakwani (2008), and Kang and Imai (2012). What is common in all of these methods is that they adopt an anonymous point of view: they compare the degree of poverty at two moments of time, but 
without considering who is poor at the beginning and who is poor at the end. In the context of the measurement of pro-poor growth, the anonymity axiom has been criticised by Grimm (2007) and Bourguignon (2011); already before that Baulch and McCulloch (2002) focused on poverty transitions.

In this paper we adopt the non-anonymous point of view. We argue that it is not only important to know whether the amount of poverty has decreased or whether the initially poor have gained more than the initially rich, but also to detect who manages to escape poverty and who falls into poverty as a result of economic growth. Put differently, when looking at the effects of growth on poverty, we have to consider both the perspective of the initially poor and that of the finally poor.

\subsection{Inequality in Vietnam}

Information on the evolution of inequality in Vietnam can be found on the PovcalNet website of the World Bank (http://iresearch.worldbank.org/PovcalNet/home.aspx) and in a few other publications. In one way or another, all this information is based on the data of Vietnamese household surveys (see section 4.1 below for more details). Although some studies have focused on per capita income, most have concentrated on per capita consumption expenditure, which is often considered as a more reliable indicator of well-being in developing countries. As far as indices are concerned, both the Gini coefficient and the Theil index have been used. Table 1 summarises the main findings of these studies. The values reported by Le and Booth (2014) are very close to those reported by Glewwe, Gragnolati and Zaman (2002) for 1993 and 1998, the two years for which we can compare their results, but exceed those reported by Benjamin, Brandt and McCaig (2017) for 2002, 2004 and 2006, the three years for which their estimates overlap. The Gini coefficients provided by PovcalNet tend to be similar to those of Le and Booth (2014) but marginally higher than those of Benjamin, Brandt and McCaig (2017). The calculations of the latter indicate that inequality of per capita income tends to be higher than inequality of per capita consumption expenditure, both for the Gini coefficient and the Theil index. Remarkably, while consumption expenditure inequality seems to have decreased between 2004 and 2008, income inequality has increased. The PovcalNet data show that inequality has decreased very slightly over the period 1993-2014, but also that the evolution has not been constant. All studies suggest that inequality reached a peak in 2010 and decreased since then. 
Several factors have been put forward as possible explanations for the observed changes. Remittances related to internal migration from rural to urban areas may have attenuated the impact of location differences and hence narrowed the urban-rural income gap (Le and Booth, 2014; Benjamin, Brandt and McCaig, 2017). The development of the wage-labour market in the whole country could also have had an alleviating effect on income inequality (Benjamin, Brandt and McCaig, 2017). At the same time, differences with respect to educational achievements, changes in the age structure of households, diversified labour market opportunities and returns (Le and Booth, 2014), geographic location (Le and Booth, 2014; Kang and Imai, 2012) and a deteriorating position of ethnic minority groups (Benjamin, Brandt and McCaig, 2017; Kang and Imai, 2012) may have contributed to increase inequality. The combined effect of these evolutions has been that per capita inequality has remained fairly steady (Benjamin, Brandt and McCaig, 2017). Nevertheless, there is evidence of a high degree of household mobility in Vietnam (McKay and Tarp, 2013).

\section{Methodology}

\subsection{Measuring the progressivity of changes in income inequality}

Assume we can observe the incomes of a given population at two moments of time, the initial period " 0 " and the final period " 1 ". Let the number of individuals be equal to $n$, and the income of person $\mathrm{i}$ in period $\mathrm{t} \mathrm{y}_{\mathrm{i}, \mathrm{t}}(\mathrm{i}=1,2, \ldots, \mathrm{n} ; \mathrm{t}=0,1)$.

Jenkins and Van Kerm (2006) have shown that if we measure income inequality by means of the Gini coefficient ${ }^{1}$, the change between the level of inequality in the final period, $\mathrm{G}_{1}$, and that in the initial period, $\mathrm{G}_{0}$, can be decomposed into two components: a progressivity component and a mobility component. The first measures to what extent the growth in incomes between the initial and the final period is concentrated more among the poor than among the rich. This component supposedly measures the degree of progressivity or of 'propoorness' of the change. The second measures the effect of changes in ranks on the level of inequality. It is possible that this effect wipes out the pro-poor character of growth.

\footnotetext{
${ }^{1}$ Actually, their framework is valid for the entire generalized Gini class of inequality measures.
} 
The decomposition relies on the calculation of an intermediate level of inequality $\mathrm{G}_{1}^{(0)}$ assuming that all persons retain the ranks they had in the initial period, but earn the incomes of the final period. The progressivity component $\mathrm{P}$ is defined as minus the effect of changing the income levels while keeping the ranks fixed at their initial levels:

$$
\mathrm{P}=-\left(\mathrm{G}_{1}^{(0)}-\mathrm{G}_{0}\right)
$$

(The minus sign is introduced in order to have $P>0$ when $G_{1}^{(0)}<G_{0}$.) The mobility or reranking component $\mathrm{R}$ is defined as the effect of changing the ranks while keeping the incomes fixed at their final levels:

$$
\mathrm{R}=\mathrm{G}_{1}-\mathrm{G}_{1}^{(0)}
$$

The total change in equality is equal to the difference between $\mathrm{R}$ and $\mathrm{P}$ :

$$
\Delta \mathrm{G}=\mathrm{G}_{1}-\mathrm{G}_{0}=\left(\mathrm{G}_{1}-\mathrm{G}_{1}^{(0)}\right)+\left(\mathrm{G}_{1}^{(0)}-\mathrm{G}_{0}\right)=\mathrm{R}-\mathrm{P}
$$

At least two objections can be raised against this approach. The first is that it evaluates the pro-poor character of the change, measured by $\mathrm{P}$, exclusively in terms of the initial situation. The ranks chosen for the evaluation of the change in incomes are those of period 0 . However, one could just as well look at the change from the point of view of the final situation, and choose the ranks of period 1 to evaluate the change in incomes. This alternative perspective requires the calculation of another intermediate level of inequality, $\mathrm{G}_{0}^{(1)}$, based on the assumption that all persons have the ranks they attain in the final period, but earn the incomes of the initial period. The progressivity component $\mathrm{P}_{\text {alt }}$ would then be defined as the effect of changing the income levels while keeping the ranks fixed at their final levels:

$$
\mathrm{P}_{\mathrm{alt}}=\mathrm{G}_{0}^{(1)}-\mathrm{G}_{1}
$$

Likewise, the mobility or re-ranking component $\mathrm{R}_{\mathrm{alt}}$ would be defined as minus the effect of changing the ranks while keeping the incomes fixed at their initial levels:

$$
\mathrm{R}_{\mathrm{alt}}=-\left(\mathrm{G}_{0}-\mathrm{G}_{0}^{(1)}\right)
$$

The total change in equality is again equal to the difference between $R_{\text {alt }}$ and $P_{\text {alt }}$ :

$$
\Delta \mathrm{G}=\mathrm{G}_{1}-\mathrm{G}_{0}=-\left(\mathrm{G}_{0}-\mathrm{G}_{0}^{(1)}\right)-\left(\mathrm{G}_{0}^{(1)}-\mathrm{G}_{1}\right)=\mathrm{R}_{\mathrm{alt}}-\mathrm{P}_{\mathrm{alt}}
$$


In general, the two progressivity components $\mathrm{P}$ and $\mathrm{P}_{\text {alt }}$, just as the two mobility components $\mathrm{R}$ and $\mathrm{R}_{\mathrm{alt}}$, are not necessarily the same, and it might very well be that they are of opposite sign. The two intermediate indices $\mathrm{G}_{0}^{(1)}$ and $\mathrm{G}_{1}^{(0)}$ are, in fact, concentration indices (Kakwani, 1980: 173-178), which can be positive, negative or zero. Given the bounds of these indices, we can derive that $\mathrm{P}_{\mathrm{alt}} \leq \mathrm{P}$ and $\mathrm{R}_{\mathrm{alt}} \leq 0 \leq \mathrm{R}$. $^{2}$ In other words, if evaluated using the incomes of the final period the re-ranking component is never negative, while if evaluated using the incomes of the initial period it is never positive.

The perspective problem is acknowledged by Jenkins and Van Kerm, because they write:

We are interested in directional change, i.e. how much aggregate inequality changes when going from some base year to some final year, with the base year social evaluation as the reference point. If, instead, changes are summarized and decomposed using the final year social evaluation as the reference point, an analogous decomposition can also be derived. In principle, there is therefore an index number issue. In practice this is less important as the forward-looking perspective is the natural one to use when examining (the progressivity of) income growth over time. (Jenkins and Van Kerm, 2006: 536, note 7)

We do not agree with their view that the forward-looking perspective, i.e. the evaluation taking the initial year as reference point, is the natural or only one which should be adopted when looking at the progressivity of a change in incomes. We argue that the evaluation of progressivity from a backward-looking perspective, i.e. taking the final year as the reference point, is equally important. Especially if there are conflicting assessments, it seems arbitrary to privilege just one point of reference. It may also be seriously misleading. It could very well be that both the change from income distribution $y_{0}$ in period 0 to income distribution $y_{1}$ in period 1 and the change from income distribution $y_{1}$ in period 1 to income distribution $\mathrm{y}_{2}=\mathrm{y}_{0}$ in period 2 (i.e., the reversal of the previous change) are evaluated as progressive. ${ }^{3}$ But how can two successive progressive changes lead to a status quo? In order to avoid this

\footnotetext{
${ }^{2}$ Since $-\mathrm{G}_{1} \leq \mathrm{G}_{1}^{(0)} \leq \mathrm{G}_{1}$, it follows that $\mathrm{G}_{0}-\mathrm{G}_{1} \leq \mathrm{P} \leq \mathrm{G}_{0}+\mathrm{G}_{1}$ and $0 \leq \mathrm{R} \leq 2 \mathrm{G}_{1}$, and since $-\mathrm{G}_{0} \leq \mathrm{G}_{0}^{(1)} \leq \mathrm{G}_{0}$, that $-\mathrm{G}_{0}-\mathrm{G}_{1} \leq \mathrm{P}_{\text {alt }} \leq \mathrm{G}_{0}-\mathrm{G}_{1}$ and $-2 \mathrm{G}_{0} \leq \mathrm{R}_{\mathrm{alt}} \leq 0$.

${ }^{3}$ Here is an example: let $\mathrm{y}_{1,0}=1, \mathrm{y}_{2,0}=5, \mathrm{y}_{3,0}=9, \mathrm{y}_{1,1}=10, \mathrm{y}_{2,1}=0, \mathrm{y}_{3,1}=5$, and $\mathrm{y}_{1,2}=1, \mathrm{y}_{2,2}=5, \mathrm{y}_{3,2}=9$.

Then: $G_{0}=G_{2}=\frac{16}{45}, G_{1}=\frac{20}{45}, G_{1}^{(0)}=-\frac{10}{45}$, and $G_{2}^{(1)}=-\frac{8}{45}$, which means that $P_{0 \rightarrow 1}=\frac{26}{45}$ and $P_{1 \rightarrow 2}=\frac{28}{45}$.
} 
kind of paradoxical results, we make a case for the evaluation of progressivity from the point of view of both the initial and the final year of the change.

This leads us to our second objection. There appears to be an inconsistency in the approach of Jenkins and Van Kerm. Although they claim that the natural reference point for social evaluation is the initial year, they adopt a different perspective for the evaluation of the mobility component. In fact, the estimate of the re-ranking component $\mathrm{R}$ is based on the income levels of the final period. No reason is given for this differential treatment. The reranking component from the point of view of the initial period, i.e. based on the income levels of the initial period, is equal to $\mathrm{R}_{\mathrm{alt}}$. If everything has to be evaluated from the point of view of the initial period, the decomposition should therefore be $\mathrm{R}_{\mathrm{alt}}-\mathrm{P}$. Unfortunately, however, in general we have $\Delta \mathrm{G} \neq \mathrm{R}_{\mathrm{alt}}-\mathrm{P}$, so that the decomposition does not seem to work.

A way out could be to develop some kind of aggregate assessment of the progressivity and mobility components based on the two points of view. One possibility would be to give equal weights to the initial and the final periods. This suggests the following aggregate progressivity and mobility components:

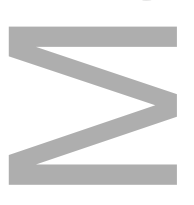

$$
\begin{aligned}
& P_{\mathrm{agg}}=\frac{P+P_{a l t}}{2}=\frac{G_{0}-G_{1}+G_{0}^{(1)}-G_{1}^{(0)}}{2} \\
& R_{\mathrm{agg}}=\frac{R+R_{a l t}}{2}=\frac{G_{1}-G_{0}+G_{0}^{(1)}-G_{1}^{(0)}}{2}
\end{aligned}
$$

It is easy to check that $\Delta \mathrm{G}=\mathrm{R}_{\mathrm{agg}}-\mathrm{P}_{\mathrm{agg}}$.

At a deeper level, one might ask why it is necessary to make a distinction between the two components. After all, re-ranking is driven by the same causes as progressivity: relative income changes. Are we not looking at two sides of the same coin?

\subsection{A formal analysis}

A more satisfactory solution can be found by following a slightly more general approach. Let us assume that we measure inequality by a 'linear' indicator of the following type:

$$
\mathrm{I}_{\mathrm{t}}=\frac{1}{\mu_{\mathrm{t}}} \frac{1}{\mathrm{n}} \sum_{\mathrm{i}=1}^{\mathrm{n}} \mathrm{w}_{\mathrm{i}, \mathrm{t}} \mathrm{y}_{\mathrm{i}, \mathrm{t}}
$$


where $\mathrm{w}_{\mathrm{i}, \mathrm{t}}$ stands for the weight given to person $\mathrm{i}$ in period $\mathrm{t}$ and $\mu_{\mathrm{t}}$ for the average income in period t. The Gini coefficient, for instance, defines the weights in terms of the ranks:

$$
\mathrm{w}_{\mathrm{i}, \mathrm{t}}=\frac{2 \mathrm{r}_{\mathrm{i}, \mathrm{t}}-\mathrm{n}-1}{\mathrm{n}}
$$

with $r_{i, t}$ equal to the rank of person $i$ in the income distribution of period $t$ (rank 1 is given to the poorest person in society, and rank $\mathrm{n}$ to the richest).

Following the idea of Jenkins and Van Kerm, we can decompose the change in inequality $\Delta \mathrm{I}=\mathrm{I}_{1}-\mathrm{I}_{0}$ into two components, one due to changes in income levels, which we denote by $\mathrm{Y}$, and another due to changes in weights, which we denote by W. As pointed out above, there are two possibilities. Using the superscript (t) to indicate that the income or weight effect is evaluated from the point of view of the situation in period $t$, we obtain the following:

$$
\begin{aligned}
& \Delta \mathrm{I}=\left(\mathrm{I}_{1}-\mathrm{I}_{1}^{(0)}\right)+\left(\mathrm{I}_{1}^{(0)}-\mathrm{I}_{0}\right)=\mathrm{W}^{(1)}+\mathrm{Y}^{(0)} \\
& \Delta \mathrm{I}=\left(\mathrm{I}_{1}-\mathrm{I}_{0}^{(1)}\right)+\left(\mathrm{I}_{0}^{(1)}-\mathrm{I}_{0}\right)=\mathrm{Y}^{(1)}+\mathrm{W}^{(0)}
\end{aligned}
$$

Here $I_{s}^{(t)}$ stands for the amount of inequality if incomes were equal to those of period s but the weights equal to those of period t. In general, the two intermediate indices $I_{0}^{(1)}$ and $I_{1}^{(0)}$ have different values. Note that if $\mathrm{I}=\mathrm{G}$, then $\mathrm{W}^{(1)}=\mathrm{R}, \mathrm{Y}^{(0)}=-\mathrm{P}, \mathrm{Y}^{(1)}=-\mathrm{P}_{\text {alt }}$, and $\mathrm{W}^{(0)}=\mathrm{R}_{\mathrm{alt}}$.

Let us now consider an alternative inequality measure, L, defined as the square of the coefficient of variation. (This is also known as twice the Generalized Entropy Index GE( $\theta)$ for the parameter value $\theta=2$.) This index is based on a weighting function determined by income levels rather than income ranks; i.e., instead of (10) we now have:

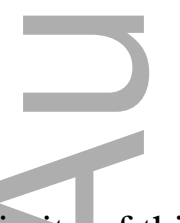

$$
\mathrm{w}_{\mathrm{i}, \mathrm{t}}=\frac{\mathrm{y}_{\mathrm{i}, \mathrm{t}}-\mu_{\mathrm{t}}}{\mu_{\mathrm{t}}}
$$

The peculiarity of this inequality measure is that the values of the two intermediate indices, $\mathrm{L}_{0}^{(1)}$ and $\mathrm{L}_{1}^{(0)}$, are exactly equal to one another. These indices are equal to the level-dependent index suggested by Erreygers and Kessels (2017) as an alternative for the rank-dependent concentration index. We therefore have: 


$$
\begin{aligned}
& \mathrm{W}^{(1)}=\mathrm{L}_{1}-\mathrm{L}_{1}^{(0)}=\mathrm{L}_{1}-\mathrm{L}_{0}^{(1)}=\mathrm{Y}^{(1)} \\
& \mathrm{Y}^{(0)}=\mathrm{L}_{1}^{(0)}-\mathrm{L}_{0}=\mathrm{L}_{0}^{(1)}-\mathrm{L}_{0}=\mathrm{W}^{(0)}
\end{aligned}
$$

Two interesting conclusions can be drawn from (14) and (15). The first is that if both the income and weight effect are evaluated from the same point of view, they are exactly equal to each other: $\mathrm{Y}^{(0)}=\mathrm{W}^{(0)}$ and $\mathrm{Y}^{(1)}=\mathrm{W}^{(1)}$. At least for this index, then, there is no real difference between the two effects. Secondly, it follows that the change in inequality can be decomposed into the sum of two income effects (or equivalently, two weight effects) evaluated from different points of view:

$$
\Delta \mathrm{L}=\mathrm{Y}^{(0)}+\mathrm{Y}^{(1)}=\mathrm{W}^{(0)}+\mathrm{W}^{(1)}
$$

Adapting the terminology of Jenkins and Van Kerm, we say that a change in incomes is progressive from the point of view of period $t$ if $\mathrm{Y}^{(\mathrm{t})}<0$, and regressive if $\mathrm{Y}^{(\mathrm{t})}>0$. Four cases can therefore be distinguished, according to whether a change is progressive or regressive from the point of view of the initial and the final period: (i) $\mathrm{Y}^{(0)}>0, \mathrm{Y}^{(1)}>0$; (ii) $\mathrm{Y}^{(0)}>0, \mathrm{Y}^{(1)}<0$; (iii) $\mathrm{Y}^{(0)}<0, \mathrm{Y}^{(1)}>0$, and (iv) $\mathrm{Y}^{(0)}<0, \mathrm{Y}^{(1)}<0$. The first case is clearly one of regressive income change, and the fourth one of progressive income change.

It follows that if inequality is measured by index L, a change of income evaluated as regressive from both points of view (i.e., situation (i)) will necessarily coincide with an increase of inequality, and a change of income twice evaluated as progressive (i.e., situation (iv)) with a decrease of inequality. Moreover, if the appraisal is ambivalent (one progressive and one regressive evaluation, as in situations (iii) and (iv)), the overall change in inequality is determined by the income effect which is the largest in size. It is unclear whether these properties hold also for other inequality measures.

We think it is instructive to determine whether a change of income is regressive or progressive both from the perspective of the initial period (that is to say, whether the income changes have been more to the advantage of the initially rich or the initially poor) and from that of the final period (whether the income changes have been more to the advantage of the finally rich or the finally poor). Especially in the case of large changes, the forward-looking and backward-looking perspectives need not coincide. As the use of the level-dependent index $L$ reveals, the overall change in inequality can be seen as determined equally by the two income effects $\mathrm{Y}^{(0)}$ and $\mathrm{Y}^{(1)}$, which capture the degree of regressivity or progressivity from 
both points of view. However, it is only for index $L$ that the overall change in inequality can be decomposed exactly in these two components, since we always have $\Delta \mathrm{L}=\mathrm{Y}^{(0)}+\mathrm{Y}^{(1)}$.

For the Gini index the decomposition is not exact, since we generally have $\Delta \mathrm{G} \neq \mathrm{Y}^{(0)}+\mathrm{Y}^{(1)}=-\mathrm{P}-\mathrm{P}_{\text {alt }}$. One might be tempted to consider $\mathrm{R}$ as a proxy for $\mathrm{Y}^{(1)}$, and to see the decomposition proposed by Jenkins and Van Kerm as an approximation of the $\mathrm{Y}^{(0)}+\mathrm{Y}^{(1)}$ decomposition. The problem, however, is that $\mathrm{R}$ is by construction nonnegative, while $\mathrm{Y}^{(1)}$ can be either positive or negative.

\subsection{Progressivity and relative income changes}

It may be informative to go a bit deeper into the 'double' progressivity standard we have suggested above. For instance, one may wonder whether it is really possible that a change of income is progressive both from the point of view of the initial period and from that of the final period. To answer this question, it is illuminating to focus on changes in relative income. A person's relative income in period $t, \mathrm{z}_{\mathrm{i}, \mathrm{t}}$, is defined as the ratio of this person income in period t to the average income in that period, i.e. $y_{i, t} / \mu_{t}$. Observe that we can rewrite (9) as:

$$
\mathrm{I}_{\mathrm{t}}=\frac{1}{\mathrm{n}} \sum_{\mathrm{i}} \mathrm{w}_{\mathrm{i}, \mathrm{t}} \mathrm{z}_{\mathrm{i}, \mathrm{t}}
$$

Likewise we have:

$$
\mathrm{I}_{\mathrm{t}}^{(\mathrm{s})}=\frac{1}{\mathrm{n}} \sum_{\mathrm{i}} \mathrm{w}_{\mathrm{i}, \mathrm{s}} \mathrm{Z}_{\mathrm{i}, \mathrm{t}}
$$

Let $\Delta z_{1}$ denote the change in relative income of person $i$ between period 0 and period 1, i.e. $\mathrm{z}_{1,1}-\mathrm{z}_{1,0} \cdot \Delta \mathrm{z}_{\mathrm{i}}>0$ means that person $\mathrm{i}$ is, in terms of relative income, better-off in period 1 than in period 0 . We then have:

$$
\begin{gathered}
\mathrm{Y}^{(0)}=\mathrm{I}_{1}^{(0)}-\mathrm{I}_{0}=\frac{1}{\mathrm{n}} \sum_{\mathrm{i}} \mathrm{W}_{\mathrm{i}, 0} \Delta \mathrm{Z}_{\mathrm{i}} \\
\mathrm{Y}^{(1)}=\mathrm{I}_{1}-\mathrm{I}_{0}^{(1)}=\frac{1}{\mathrm{n}} \sum_{\mathrm{i}} \mathrm{W}_{\mathrm{i}, 1} \Delta \mathrm{Z}_{1}
\end{gathered}
$$


Given that the weights $\mathrm{w}_{0}$ and $\mathrm{w}_{1}$ as well as the changes in relative income $\Delta \mathrm{z}$ have averages equal to zero, it follows that $\mathrm{Y}^{(0)}=\operatorname{Cov}\left(\mathrm{w}_{0}, \Delta \mathrm{z}\right)$ and $\mathrm{Y}^{(1)}=\operatorname{Cov}\left(\mathrm{w}_{1}, \Delta \mathrm{z}\right)$. This means that $\mathrm{Y}^{(0)}$ and $\mathrm{Y}^{(1)}$ measure to what extent the changes in relative income are correlated to the initial and final weights. Since the weights are the lowest for the poor and the highest for the rich, a negative correlation indicates that increases in relative income tend to be concentrated more among the poor than among the rich, and decreases more among the rich than among the poor. $\mathrm{Y}^{(\mathrm{t})}<0$ is therefore a sign of changes being on the whole more beneficial to those who are relatively poor in period t. This is what we understand by progressivity from the perspective of period $t$.

It is by no means impossible or exceptional that a change is progressive both from the perspective of the initial and from that of the final period. A good example is the case where everyone's income increases by the same absolute amount. However, when the change involves a lot of people moving up and down the income distribution, the likelihood that $\mathrm{Y}^{(1)}$ is positive, and therefore that the change is deemed regressive from the point of view of the final period, becomes much higher. If we use the $\mathrm{L}$ index to measure $\mathrm{Y}^{(0)}$ and $\mathrm{Y}^{(1)}$, we can moreover show that we always have $Y^{(0)} \leq Y^{(1)}$, with the equality sign holding only if all relative incomes remain the same. ${ }^{4}$ This implies that a change which passes the backwardlooking progressivity test (i.e., for which we have $\mathrm{Y}^{(1)}<0$ ) automatically satisfies the forward-looking test $\left(\mathrm{Y}^{(0)}<0\right)$, but the reverse does not hold. One might also say there is a higher probability that a change is evaluated as progressive when the forward-looking perspective is adopted, and a higher probability that it is evaluated as regressive when the backward-looking perspective is adopted.

\section{Empirical analysis}

\subsection{Data description}

Our data come from the two nationally representative household surveys for Vietnam, the Vietnam Living Standards Survey (VLSS) and its successor the Vietnam Household Living

\footnotetext{
${ }^{4}$ Since we have $\mathrm{Y}^{(0)}-\mathrm{Y}^{(1)}=\frac{1}{\mathrm{n}} \sum_{\mathrm{i}}\left(\mathrm{w}_{\mathrm{i}, 0}-\mathrm{w}_{\mathrm{i}, 1}\right) \Delta \mathrm{z}_{\mathrm{i}}$ and $\mathrm{w}_{\mathrm{i}, 0}-\mathrm{w}_{\mathrm{i}, 1}=\frac{\mathrm{y}_{\mathrm{i}, 0}-\mu_{0}}{\mu_{0}}-\frac{\mathrm{y}_{\mathrm{i}, 1}-\mu_{1}}{\mu_{1}}=-\Delta \mathrm{z}_{\mathrm{i}}$, it follows that $\mathrm{Y}^{(0)}-\mathrm{Y}^{(1)}=-\frac{1}{\mathrm{n}} \sum_{\mathrm{i}}\left(\Delta \mathrm{z}_{\mathrm{i}}\right)^{2} \leq 0$
} 
Standards Survey (VHLSS), which provide detailed information on the incomes and consumption expenditures of Vietnamese households. The two VLSS surveys were taken in 1993 and 1998, while the VHLSS surveys have been taken every two years since $2002{ }^{5}$ The data from these surveys have been used in many empirical studies of living standards in Vietnam.

The survey data include population weights in order to make the surveys representative for the Vietnamese population of the year in which the survey is taken. The sample populations of successive survey years typically overlap, but only partially so. About half of the households are resurveyed in the next wave of the survey, which allows us to generate panel data from cross-sectional data for short periods of time. We constructed three panels by selecting households that were surveyed in both the initial and the final year of the chosen time periods (1993-1998, 2002-2006, and 2004-2008). Households that split into two independent households in the period in between were not included.

It should be noted that our panel data are probably not perfectly representative for the Vietnamese population. The sample size of the panels is rather small, and moreover we do not know which population weights should be applied in order to make the panels representative for the Vietnamese population over the periods under consideration. In this paper, we always employ the population weights of households in the final survey year of the panels.

We use equivalised real per capita consumption expenditure as a proxy to measure individual income. Equivalised real per capita consumption expenditure is equal to the real household consumption expenditure divided by the square root of the number of individuals in the household. All expenditures are expressed in 2012 prices and adjusted by regional price deflators. The descriptive statistics of our variable of interest for the successive waves of the survey can be found in Table 2. Table 3 gives the same information for the three panels we have constructed. Clearly, if we use panel data to study inequality in Vietnam, the results should be treated with caution.

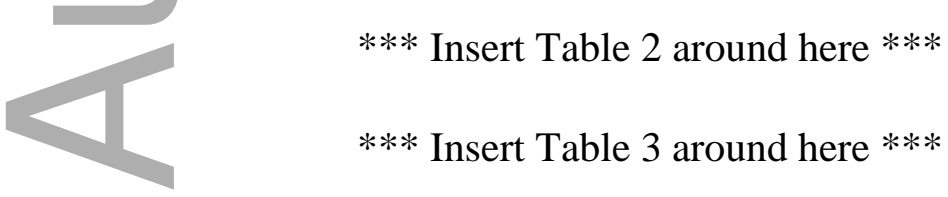

\footnotetext{
${ }^{5}$ More information can be found on the Living Standard Survey page of the General Statistics Office of Vietnam.
} 


\subsection{The evolution of inequality}

We begin by looking at the evolution of inequality of equivalised real per capita consumption expenditure in Vietnam between 1993 and 2012 according to both the full survey data and the panel data we constructed. Figure 1 represents the evolution of inequality as measured by the Gini coefficient (left panel) and the L index (right panel).Comparing the inequality indices estimated on the basis of our panel data to those based on the full cross-sectional data of the surveys, we observe that the panel estimates tend to be slightly lower for the Gini coefficient, while no clear pattern emerges for the $\mathrm{L}$ index. The values of the Gini coefficient also seem to be more stable over time than those of the Lindex.

*** Insert Figure 1 around here $* * *$

According to the Gini coefficient the level of inequality remained more or less the same between 1993 and 1998, rose between 1993 and 2002, remained fairly stable between 2002 and 2010 and substantially decreased between 2010 and 2012. Our estimates of the Gini coefficient tend to be a little bit smaller than those of the World Bank, and for the years 2010 and 2012 more substantially so (see the PovcalNet estimates reported in Table 1 above). The values of the Lindex follow a roughly similar pattern, but show an increase between 1993 and 1998, a decrease between 2002 and 2006 and an increase between 2006 and 2010. The panel estimates appear to fluctuate more strongly than the survey estimates, which once again suggests that we have to be careful in the interpretation of the panel data results.

\subsection{The decomposition results}

We now follow the methodologies explained in Section 3 to decompose the change in inequality into different components. Table 4 presents the results of the decomposition analysis for our three Vietnamese panel data sets.

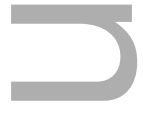

$* * *$ Insert Table 4 around here ***

If we use the Gini coefficient to measure inequality, we find an insignificant change between 1993 and 1998, and small decrease between 2002 and 2006 and a larger decrease between 2004 and 2008. According to the methodology of Jenkins and Van Kerm, in all three cases the change is evaluated as progressive, as can be seen from the negative values of the progressivity component $-\mathrm{P}$. Moreover, the absolute magnitude of this component has increased slightly over time. But $-\mathrm{P}$ measures progressivity only from the perspective of the 
initial period. The alternative progressivity component we suggested, $-\mathrm{P}_{\text {alt }}$, indicates that none of the changes is evaluated as progressive from the perspective of the final period. The absolute value of this component has decreased over time. While for the first panel the two progressivity components are perfectly poised, for the two other panels the $-\mathrm{P}$ component dominates the $-\mathrm{P}_{\text {alt }}$ component. The value of the re-ranking components $\mathrm{R}$ and $\mathrm{R}_{\mathrm{alt}}$ does not change very much from one panel to the other.

We obtain slightly different results if we use the L index to measure inequality. The level of inequality slightly increases between 1993 and 1998, strongly decreases between 2002 and 2006 and again decreases, but to a less extent, between 2004 and 2008. The values of $\mathrm{Y}^{(0)}$ are significantly negative, which means that for all panels we have forward-looking progressivity. In absolute terms, the value of this component is the highest in the second panel. The values of $\mathrm{Y}^{(1)}$, on the other hand, are all significantly positive, which indicates that for none of the panels the change is backward-looking progressive. In absolute terms the value of $\mathrm{Y}^{(1)}$ is the lowest for the second panel. One could say that between 2002 and 2006 the change is close to being progressive from the perspective of both the initial and the final period.

Broadly speaking, the two methodologies yield similar results: for all panels the changes are forward-looking progressive, but not backward-looking progressive. Nevertheless, they differ in their assessments of the degree of forward-looking and backward-looking progressivity. This can be measured by the ratio of the two components for each methodology, respectively $\mathrm{P} / \mathrm{P}_{\text {alt }}$ and $\mathrm{Y}^{(0)} / \mathrm{Y}^{(1)}$. We report the forward/backward progressivity ratios in Table 5. There is a striking difference between the ratios of the two methodologies for the panel 2002-2006.

$$
\text { *** Insert Table } 5 \text { around here } * * *
$$

\section{Discussion}

\subsection{Wagstaff's decomposition results}

We are not the first to apply the decomposition methodology of Jenkins and Van Kerm to Vietnam. Wagstaff (2009) used and extended their approach to explore whether economic growth in China and Vietnam benefited the poor, in relative or absolute terms. He emphasised that pro-poor growth must be understood as growth that is to the benefit of those who are initially poor. Since for Vietnam he used the same data as we did, we can compare his results 
to ours for two of the three panels (Wagstaff did not consider the 2004-2008 panel). The only difference is that Wagstaff considered real per capita consumption expenditures, while we looked at equivalised real per capita consumption expenditures. In order to make the results comparable, we redid our calculations of the Jenkins-Van Kerm decomposition using the same expenditure concept as Wagstaff. Table 6 represents his and our estimations of the decomposition. It should be noted that our results remain fairly close to those reported in Table 4.

*** Insert Table 6 around here ***

Comparing Wagstaff's results to ours, we observe that there are small differences in the estimated levels of inequality, especially for the initial year of each panel. These might be due to the inclusion or exclusion of a few households reporting extremely high consumption expenditures. More worrisome is that Wagstaff gives consistently lower estimates for the two components of the decomposition, $\mathrm{R}$ and -P, especially for the first panel. It seems unlikely that these differences are caused by a few outliers, but we have no idea what else might explain them. Wagstaff (2009: 1418) duly noted that his estimates of the relative magnitudes $\mathrm{R} / \mathrm{G}_{0}$ and $-\mathrm{P} / \mathrm{G}_{0}$ for Vietnam were low in comparison to those he obtained for China. Our estimates for Vietnam are still much lower than those for China, but are quite similar to the ones obtained for the US and Germany by Jenkins and Van Kerm (2006). We believe it could be possible that the results for Vietnam reported by Wagstaff are underestimations.

\subsection{A visualisation of the change in inequality}

In section 3.3 we pointed out that the progressivity measures $\mathrm{Y}^{(0)}$ and $\mathrm{Y}^{(1)}$ can be expressed as the covariance between the initial and final weights on the one hand, and the changes in relative incomes on the other. This allows a straightforward visual representation of the two measures. We illustrate here how this can be done for the two progressivity components derived from the Lindex; it is also possible to do this for the Gini coefficient.

Since we are working with consumption expenditure rather than income data, $\mathrm{z}_{\mathrm{i}, 0}=\mathrm{y}_{\mathrm{i}, 0} / \mu_{\mathrm{y}, 0}$ and $\mathrm{z}_{\mathrm{i}, 1}=\mathrm{y}_{\mathrm{i}, 1} / \mu_{\mathrm{y}, 1}$ represent relative expenditure rather than relative income of individual $\mathrm{i}$ at times 0 and 1 , respectively. We call $\mathrm{z}_{1,0}^{*} \equiv \mathrm{z}_{1,0} / \operatorname{var}\left(\mathrm{z}_{0}\right)$ and $\mathrm{z}_{1,1}^{*} \equiv \mathrm{z}_{1,1} / \operatorname{var}\left(\mathrm{z}_{1}\right)$ the standardised relative expenditure of individual i at times 0 and 1 , respectively. Let us now draw two scatter 
diagrams, one where individuals are represented by the points $\left(\Delta z_{1}, z_{1,0}^{*}\right)$ and the other where they are represented by the points $\left(\Delta \mathrm{z}_{1}, \mathrm{z}_{1,1}^{*}\right)$. It can be shown that the slope $\beta_{0}$ of the simple regression equation $\Delta \mathrm{z}_{1}=\alpha_{0}+\beta_{0} \mathrm{z}_{0, \mathrm{i}}^{*}+\varepsilon_{0, \mathrm{i}}$ is equal to $\mathrm{Y}^{(0)}$, and the slope $\beta_{1}$ of $\Delta \mathrm{z}_{\mathrm{i}}=\alpha_{1}+\beta_{1} \mathrm{z}_{1, \mathrm{i}}^{*}+\varepsilon_{1, \mathrm{i}}$ equal to $\mathrm{Y}^{(1)}$. This means that the two progressivity components coincide with the slopes of the regression lines through the two scatter diagrams. For a change to be progressive from the perspective of both the initial and the final period of a panel, the slopes of the two regression lines have to be negative.

Figure 2 illustrates this for our three Vietnamese panels. The figures on the left reflect the forward-looking perspective, and those on the right the backward-looking perspective. The regression lines are represented in red. With regard to the forward-looking component, the relatively steep slopes of the regression lines for the 2002-2006 and 2004-2008 panels indicate that for these panels the absolute magnitude of $\mathrm{Y}^{(0)}$ is substantially higher than that for the 1993-1998 panel. As far as the backward-looking component is concerned, the almost flat slope of the regression line for the 2002-2006 panel demonstrates that for this panel the value of $\mathrm{Y}^{(1)}$ is relatively low.

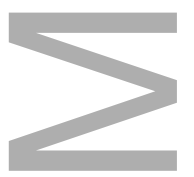

*** Insert Figure 2 around here $* * *$

\subsection{Alternative decomposition techniques}

The final issue we would like to discuss concerns the scope and limitation of the approach adopted in this paper. The focus is on the measurement of the degree of progressivity of economic growth, by means of a decomposition of the change in levels of inequality. The necessity of panel data seriously limits the applicability of the suggested decomposition method. Household surveys are often not balanced or unbalanced panels, and even if they are, they may be too small or not representative for the population. It would certainly be useful to complement the analysis by decomposition methods which allow to exploit more fully the rich amount of data which household surveys usually provide.

In the literature of income and wage inequality several attempts have been made in that direction. The idea is to start from a model which explains the observed distribution at a given moment of time using a wide array of relevant variables, such as sex, marital status and education level. For this traditional regression techniques have been used (e.g., Blau and 
Kahn, 1995), but in recent years more sophisticated regression methods have become increasingly popular, such as quantile regression (e.g., Machado and Mata, 2005) and the flexible regression approach based upon a proportional-hazards specification (e.g., Donald, Green and Paarsch, 2000). If data are available for two different moments of time, say $t=0$ and $\mathrm{t}=1$, it becomes possible to decompose the change in any distributional statistic between $\mathrm{t}=0$ and $\mathrm{t}=1$ by constructing a counterfactual distribution. One counterfactual is obtained by combining the estimated coefficients of $\mathrm{t}=0$ with the data of $\mathrm{t}=1$; alternatively, the estimated coefficients of $t=1$ could be combined with the data of $t=0$. The change in the distributional statistic, say the Gini coefficient, can then be decomposed into the sum of the effect of changes in the coefficients, the effect of changes in the data (e.g. increases in the levels of education), and a residual term.

The main advantage of these decomposition approaches is that they allow to dig much deeper into the mechanisms behind the observed changes in inequality. As a result, the analysis is more relevant when it comes to policy recommendations. Whereas the Jenkins-Van Kerm type of decomposition sheds light on the degree to which economic growth is progressive, the alternative decomposition approaches help understand why inequality has changed the way it has. It is obvious that for a thorough understanding of the implications of economic growth on inequality one has to rely on these more advanced decomposition techniques.

\section{Conclusion}

In this paper we have reconsidered how pro-poor growth is characterised and have taken a critical look at the definition of progressivity proposed by Jenkins and Van Kerm (2006). Their methodology relies on a decomposition of the change in the Gini coefficient into two components. The progressivity component evaluates the change exclusively from the point of view of the initial period. We argue that pro-poorness should be evaluated both from the perspective of the initial period and from the perspective of the final period, and propose a new decomposition methodology based on the change of a level-dependent rather than rankdependent index of inequality. An application of both methodologies to Vietnamese panel data allows us to assess their differences and to evaluate whether economic growth has been pro-poor in Vietnam. 


\section{References}

Baulch, B. and McCulloch, N. (2002). Being poor and becoming poor: Poverty status and poverty transitions in rural Pakistan. Journal of Asian and African Studies, 37(2): 168-185.

Benjamin, D., Brandt, L. and McCaig, B. (2017). Growth with equity: Income inequality in Vietnam, 2002-14. Journal of Economic Inequality, 15(1), 25-46.

Blau, F.D. and Kahn, L.M. (1996). International differences in male wage inequality: Institutions versus market forces. Journal of Political Economy, 104(4), 791-837.

Bourguignon, F. (2011). Non-anonymous growth incidence curves, income mobility and social welfare dominance. Journal of Economic Inequality, 9(4): 605-627.

Donald, S.G., Green, D.A. and Paarsch, H.J. (2000). Differences in the wage distributions between Canada and the United States: An application of a flexible estimator of the distribution function in the presence of covariates. Review of Economic Studies, 67(4), 609633.

Erreygers, G. and Kessels, R. (2017). Socioeconomic status and health: A new approach to the measurement of bivariate inequality. International Journal of Environmental Research and Public Health, 14(7): 673.

Fritzen, S. (2002). Growth, inequality and the future of poverty reduction in Vietnam. Journal of Asian Economics, 13(5): 635-657.

Glewwe, P., Gragnolati, M. and Zaman, H. (2002). Who gained from Vietnam's boom in the 1990s? Economic Development and Cultural Change, 50(4): 773-792.

Grimm, M. (2007). Removing the anonymity axiom in assessing pro-poor growth. Journal of Economic Inequality, 5(2): 179-197.

Grosse, M., Harttgen, K. and Klasen, S. (2008). Measuring pro-poor growth in non-income dimensions. World Development, 36(6): 1021-1047.

Jenkins, S.P. and Van Kerm, P. (2006). Trends in income inequality, pro-poor income growth, and income mobility. Oxford Economic Papers, 58(3): 531-548.

Kakwani, N. (1980). Income Inequality and Poverty. Methods of Estimation and Policy Applications. New York: Oxford University Press. 
Kakwani, N. and Pernia, E.M. (2000). What is pro-poor growth? Asian Development Review, 18(1): 1-16.

Kakwani, N. and Son, H.H. (2004). Pro-poor growth: Concepts and measurement with country case studies. Pakistan Development Review, 42(4): 417-440.

Kakwani, N. and Son, H.H. (2008). Poverty equivalent growth rate. Review of Income and Wealth, 54(4): 643-655.

Kang, W. and Imai, K.S. (2012). Pro-poor growth, poverty and inequality in rural Vietnam. Journal of Asian Economics, 23(5): 527-539.

Le, H. and Booth, A.L. (2014). Inequality in Vietnamese urban-rural living standards, 19932006. Review of Income and Wealth, 60(4): 862-886.

Machado, J.A.F. and Mata, J. (2005). Counterfactual decomposition of changes in wage distributions using quantile regression. Journal of Applied Econometrics, 20(4): 445-465.

McCulloch, N. and Baulch, B. (1999). Assessing the Poverty Bias of Growth Methodology and an Application to Andhra Pradesh and Uttar Pradesh. Brighton, UK: Institute for Development Studies, IDS Working Paper No. 98.

McKay, A. and Tarp, F. (2013). Diversity Among Rapid Transformation: Welfare Dynamics in Rural Vietnam, 2006 to 2012. Mimeo.

(http://www.econ.ku.dk/ftarp/Publications/Docs/diversity_among_rapid_transformation.pdf)

Ravallion, M. and Chen, S. (2003). Measuring pro-poor growth. Economics Letters, 78(1): 93-99.

Ravallion, M. (2004). Pro-poor Growth: A Primer. Washington: World Bank, World Bank Policy Research Working Paper No 3242.

Son, H.H. (2003). A new poverty decomposition. Journal of Economic Inequality, 1(2): 181187.

Son, H.H. and Kakwani, N. (2008). Global estimates of pro-poor growth. World Development, 36(6): 1048-1066.

Wagstaff, A. (2009). Reranking and pro-poor growth: Decompositions for China and Vietnam. Journal of Development Studies, 45(9): 1403-1425. 
Table 1: Gini and Theil coefficients for Vietnam, 1993-2014, estimated by different authors

\begin{tabular}{|c|c|c|c|c|c|c|c|c|c|}
\hline Authors & 1993 & 1998 & 2002 & 2004 & 2006 & 2008 & 2010 & 2012 & 2014 \\
\hline \multicolumn{10}{|c|}{ Gini - per capita expenditure } \\
\hline Glewwe et al. & 0.329 & 0.352 & & & & & & & \\
\hline Le and Booth & 0.330 & 0.350 & 0.370 & 0.370 & 0.360 & & & & \\
\hline Benjamin et al. & & & 0.347 & 0.355 & 0.341 & 0.342 & 0.392 & 0.358 & 0.336 \\
\hline PovcalNet & 0.357 & 0.354 & 0.370 & 0.368 & 0.358 & 0.356 & 0.393 & 0.356 & 0.348 \\
\hline \multicolumn{10}{|c|}{ Theil - per capita expenditure } \\
\hline Glewwe et al. & 0.197 & 0.230 & & & & & & & \\
\hline Le and Bor & 0.200 & 0.230 & 0.250 & 0.240 & 0.230 & & & & \\
\hline Benjamin e & & & 0.212 & 0.218 & 0.196 & 0.193 & 0.269 & 0.217 & 0.200 \\
\hline \multicolumn{10}{|c|}{ Gini - per capita income } \\
\hline Benjamin et al & & & 0.375 & 0.370 & 0.374 & 0.389 & 0.396 & 0.375 & 0.360 \\
\hline \multicolumn{10}{|c|}{ Theil - per capita income } \\
\hline Benjamin et al. & & & 0.255 & 0.249 & 0.255 & 0.278 & 0.281 & 0.252 & 0.225 \\
\hline
\end{tabular}

Source: Glewwe, Gragnolati and Zaman (2002), Le and Booth (2014), Benjamin, Brandt and McCaig (2017), PovcalNet - World Bank (http://iresearch.worldbank.org/PovcalNet/povOnDemand.aspx; consulted on 6 August 2018).

Table 2: Descriptive statistics of equivalised real per capita consumption expenditure according to the VLSS/VHLSS surveys

\begin{tabular}{lrrrrrrrr}
\hline & 1993 & 1998 & 2002 & 2004 & 2006 & 2008 & 2010 & \multicolumn{1}{c}{2012} \\
\hline $\mathrm{N}$ & 4,793 & 6,002 & 29,519 & 9,182 & 9,185 & 9,188 & 9,398 & 9,398 \\
Mean* & 12,161 & 17,335 & 19,367 & 22,979 & 24,778 & 26,654 & 35,732 & 37,376 \\
S.D.* & 9,035 & 13,464 & 15,829 & 17,861 & 18,148 & 20,469 & 30,938 & 28,389 \\
Min* & 1,505 & 2,136 & 1,673 & 1,884 & 1,805 & 1,729 & 2,491 & 1,968 \\
Max* & 115,469 & 211,158 & 287,366 & 192,698 & 199,512 & 264,570 & 582,441 & 959,403 \\
Gini index & 0.335 & 0.337 & 0.358 & 0.360 & 0.348 & 0.347 & 0.353 & 0.330 \\
Lindex & 0.552 & 0.603 & 0.668 & 0.604 & 0.577 & 0.612 & 0.750 & 0.577
\end{tabular}

Notes: $\mathrm{N}$ is the number of households. The mean, the standard deviation and the inequality indices are calculated using the population weights provided by the survey of the year under consideration. Values with a '*' are

This article is protected by copyright. All rights reserved 
expressed in thousands of constant 2012 VND.

Source: Own calculations based on VLSS 1993, 1998 and VHLSS 2002-2012.

Table 3: Descriptive statistics of equivalised real per capita consumption expenditure according to the VLSS/VHLSS panel data

\begin{tabular}{|c|c|c|c|c|c|c|}
\hline \multirow{2}{*}{$\begin{array}{l}\text { Panel } \\
\text { Year }\end{array}$} & \multicolumn{2}{|c|}{ 1993-1998 } & \multicolumn{2}{|c|}{ 2002-2006 } & \multicolumn{2}{|c|}{ 2004-2008 } \\
\hline & 1993 & 1998 & 2002 & 2006 & 2004 & 2008 \\
\hline $\mathrm{N}$ & \multicolumn{2}{|c|}{4,295} & \multicolumn{2}{|c|}{1,863} & \multicolumn{2}{|c|}{1,799} \\
\hline Mean* & 11,522 & 15,615 & 17,968 & 22,912 & 21,960 & 25,741 \\
\hline S.D.* & 7,846 & 10,994 & 15,441 & 15,039 & 18,634 & 18,855 \\
\hline Min* & 1,505 & 2,136 & 2,331 & 2,735 & 2,568 & 2,809 \\
\hline Max* & 107,215 & 181,617 & 258,648 & 118,541 & 192,698 & 234,054 \\
\hline Gini index & 0.309 & 0.306 & 0.343 & 0.327 & 0.358 & 0.326 \\
\hline L index & 0.464 & 0.496 & 0.738 & 0.431 & 0.720 & 0.537 \\
\hline
\end{tabular}

Notes: $\mathrm{N}$ is the number of households in the panel. The mean, the standard deviation and the inequality indices are calculated using the population weights provided by the survey of the final year of the panel under consideration. Values with a '*' are expressed in thousands of constant 2012 VND. Source: Own calculations based on VLSS 1993, 1998 and VHLSS 2002-2008.

Table 4: Decomposition of the change in inequality of equivalised real per capita consumption expenditure in Vietnam by two different approaches

\begin{tabular}{cccc|cccc}
\hline Indices & $1993-98$ & $2002-06$ & $2004-08$ & Indices & $1993-98$ & $2002-06$ & $2004-08$ \\
& \multicolumn{3}{c}{ Jenkins and Van Kerm approach } & & \multicolumn{3}{c}{ Our approach } \\
\hline $\mathrm{G}_{0}$ & 0.309 & 0.343 & 0.358 & $\mathrm{~L}_{0}$ & 0.464 & 0.738 & 0.720 \\
& $(0.005)$ & $(0.013)$ & $(0.014)$ & & $(0.001)$ & $(0.006)$ & $(0.004)$ \\
$\mathrm{G}_{1}$ & 0.306 & 0.327 & 0.326 & $\mathrm{~L}_{1}$ & 0.496 & 0.431 & 0.537 \\
& $(0.005)$ & $(0.006)$ & $(0.009)$ & & $(0.001)$ & $(0.001)$ & $(0.002)$ \\
\multirow{2}{*}{$\Delta \mathrm{G}$} & -0.003 & -0.016 & -0.032 & $\Delta \mathbf{L}$ & 0.032 & -0.308 & -0.183 \\
& $(0.005)$ & $(0.011)$ & $(0.012)$ & & $(0.001)$ & $(0.006)$ & $(0.004)$ \\
$\mathrm{G}_{1}^{(0)}$ & 0.222 & 0.241 & 0.241 & $\mathrm{~L}_{1}^{(0)}$ & 0.320 & 0.351 & 0.394 \\
\hline
\end{tabular}




\begin{tabular}{cccc|cccc} 
& $(0.005)$ & $(0.007)$ & $(0.008)$ & & $(0.001)$ & $(0.001)$ & $(0.002)$ \\
$\mathrm{R}$ & 0.084 & 0.087 & 0.085 & $\mathrm{~W}^{(1)}$ & 0.176 & 0.080 & 0.143 \\
& $(0.003)$ & $(0.004)$ & $(0.006)$ & & $(0.001)$ & $(0.001)$ & $(0.002)$ \\
$\mathbf{- P}$ & $\mathbf{- 0 . 0 8 7}$ & $\mathbf{- 0 . 1 0 3}$ & $\mathbf{- 0 . 1 1 7}$ & $\mathbf{Y}^{(\mathbf{0})}$ & $-\mathbf{0 . 1 4 4}$ & $-\mathbf{0 . 3 8 7}$ & $\mathbf{- 0 . 3 2 6}$ \\
& $(0.005)$ & $(0.012)$ & $(0.011)$ & & $(0.000)$ & $(0.005)$ & $(0.002)$ \\
$\mathrm{G}_{0}^{(1)}$ & 0.220 & 0.259 & 0.271 & $\mathrm{~L}_{0}^{(1)}$ & 0.320 & 0.351 & 0.394 \\
& $(0.005)$ & $(0.010)$ & $(0.010)$ & & $(0.001)$ & $(0.001)$ & $(0.002)$ \\
$\mathrm{R}_{\text {alt }}$ & -0.090 & -0.085 & -0.088 & $\mathrm{~W}^{(0)}$ & -0.144 & -0.387 & -0.326 \\
& $(0.004)$ & $(0.005)$ & $(0.006)$ & & $(0.000)$ & $(0.005)$ & $(0.002)$ \\
$-\mathbf{P}_{\text {alt }}$ & $\mathbf{0 . 0 8 7}$ & $\mathbf{0 . 0 6 9}$ & $\mathbf{0 . 0 5 5}$ & $\mathbf{Y}^{(\mathbf{1})}$ & $\mathbf{0 . 1 7 6}$ & $\mathbf{0 . 0 8 0}$ & $\mathbf{0 . 1 4 3}$ \\
& $(0.005)$ & $(0.013)$ & $(0.014)$ & & $(0.001)$ & $(0.001)$ & $(0.002)$
\end{tabular}

Note: Bootstrap standard errors are computed on 1000 replications and shown in parentheses.

Table 5: Forward/backward progressivity ratios

\begin{tabular}{lccc}
\hline & $1993-1998$ & $2002-2006$ & $2004-2008$ \\
\hline $\mathrm{P} / \mathrm{P}_{\mathrm{alt}}$ & $-100 \%$ & $-149 \%$ & $-213 \%$ \\
$\mathrm{Y}^{(0)} / \mathrm{Y}^{(1)}$ & $-82 \%$ & $-486 \%$ & $-228 \%$ \\
\hline
\end{tabular}

Source: own calculations.

Table 6: Comparison of the Jenkins-Van Kerm decomposition of the change in inequality of real per capita consumption expenditure for Vietnam

\begin{tabular}{lcccc}
\hline & \multicolumn{2}{c}{$1993-1998$} & \multicolumn{2}{c}{$2002-2006$} \\
\cline { 2 - 5 } & Our study & Wagstaff & Our study & Wagstaff \\
\hline $\mathrm{N}$ & 4295 & 4302 & 1863 & 1885 \\
$\mathrm{G}_{0}$ & 0.309 & 0.322 & 0.359 & 0.370 \\
$\mathrm{G}_{1}$ & 0.317 & 0.317 & 0.343 & 0.340 \\
$\Delta \mathrm{G}$ & 0.008 & -0.005 & -0.016 & -0.031 \\
$\mathrm{R}$ & 0.091 & 0.043 & 0.088 & 0.065 \\
$-\mathrm{P}$ & -0.084 & -0.048 & -0.104 & -0.095 \\
$\Delta \mathrm{G} / \mathrm{G}_{0}$ & $3 \%$ & $-2 \%$ & $-4 \%$ & $-8 \%$
\end{tabular}




\begin{tabular}{lrrrr}
$\mathrm{R} \mathrm{G}_{0}$ & $29 \%$ & $13 \%$ & $25 \%$ & $17 \%$ \\
$-\mathrm{P} / \mathrm{G}_{0}$ & $-27 \%$ & $-15 \%$ & $-29 \%$ & $-26 \%$ \\
\hline
\end{tabular}

Source: Own calculations and Wagstaff (2009, Table 1).

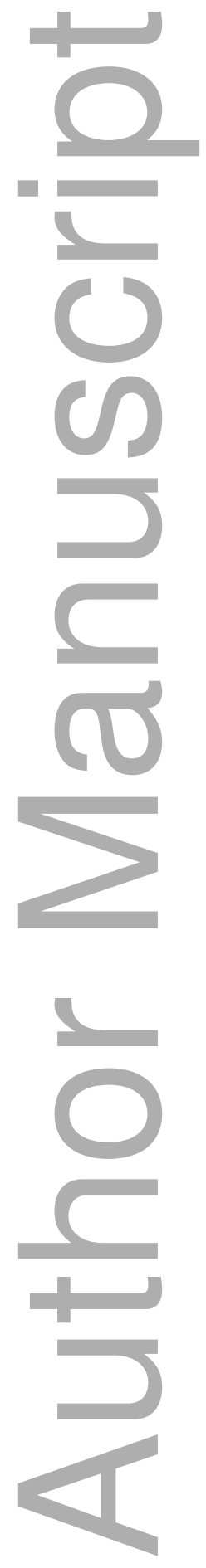


Gini index

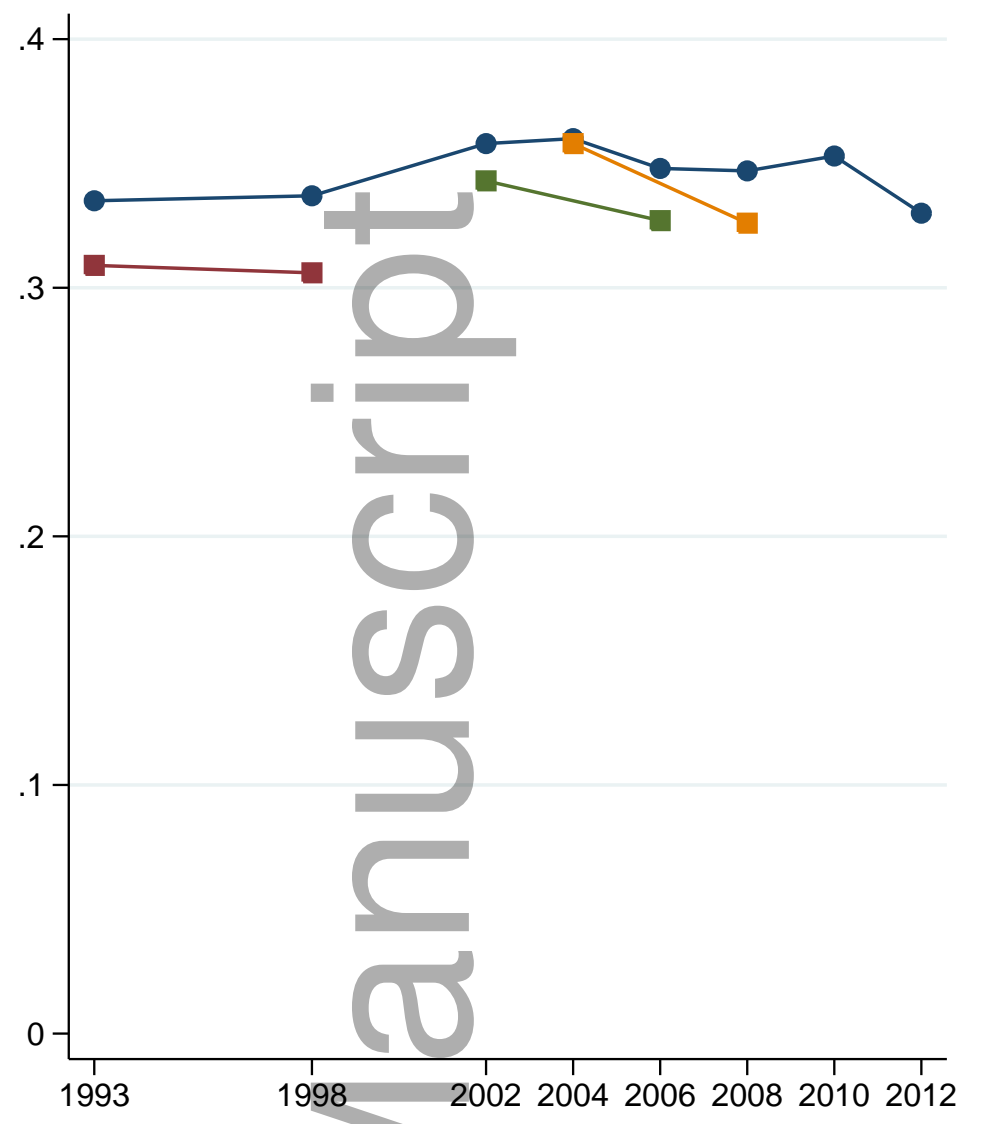

L index

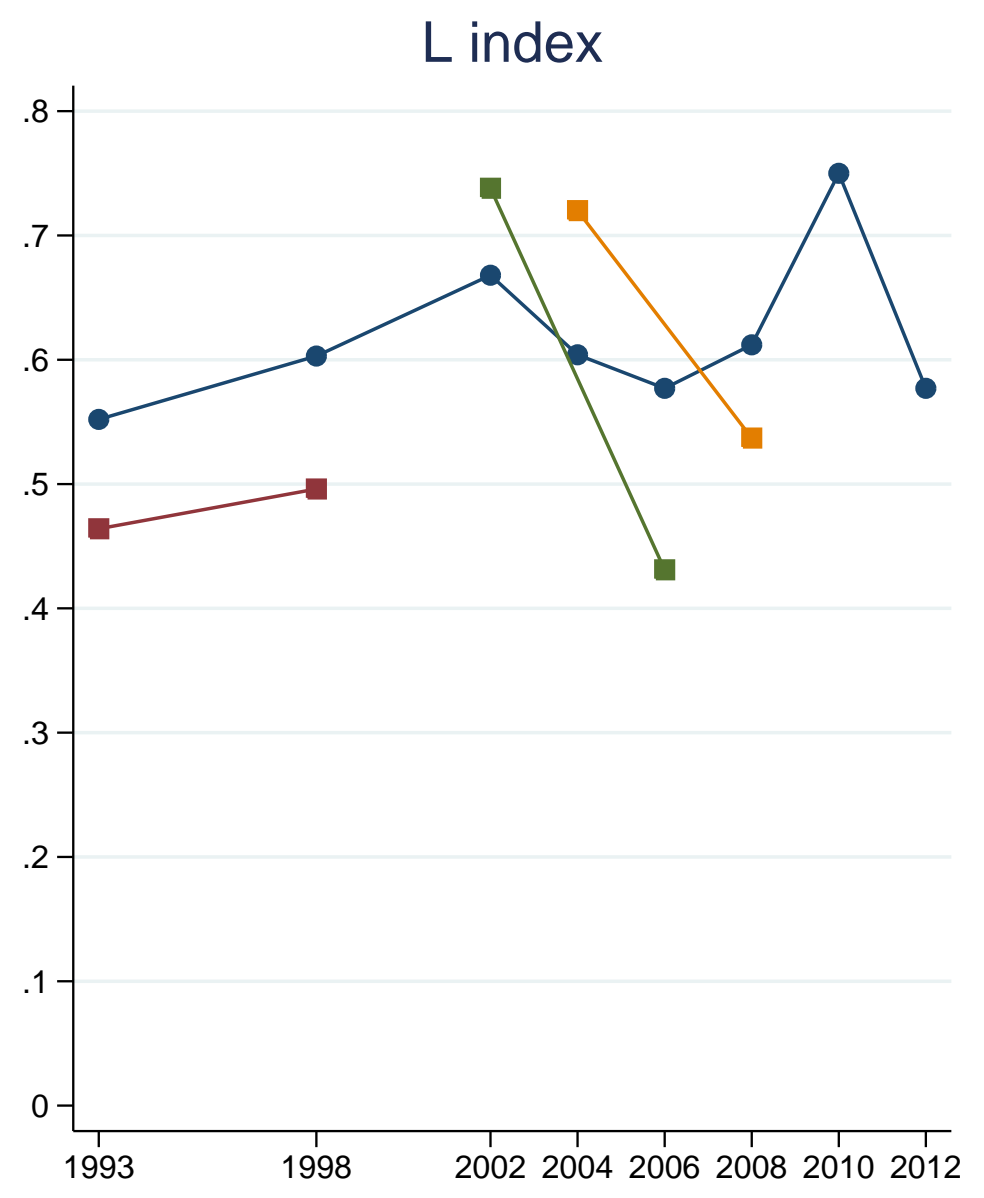

panel data, 1993-1998

panel data, 2004-2008 cross section data

panel data, 2002-2006

rode_12576_f1.eps

This article is protected by copyright. All rights reserved 

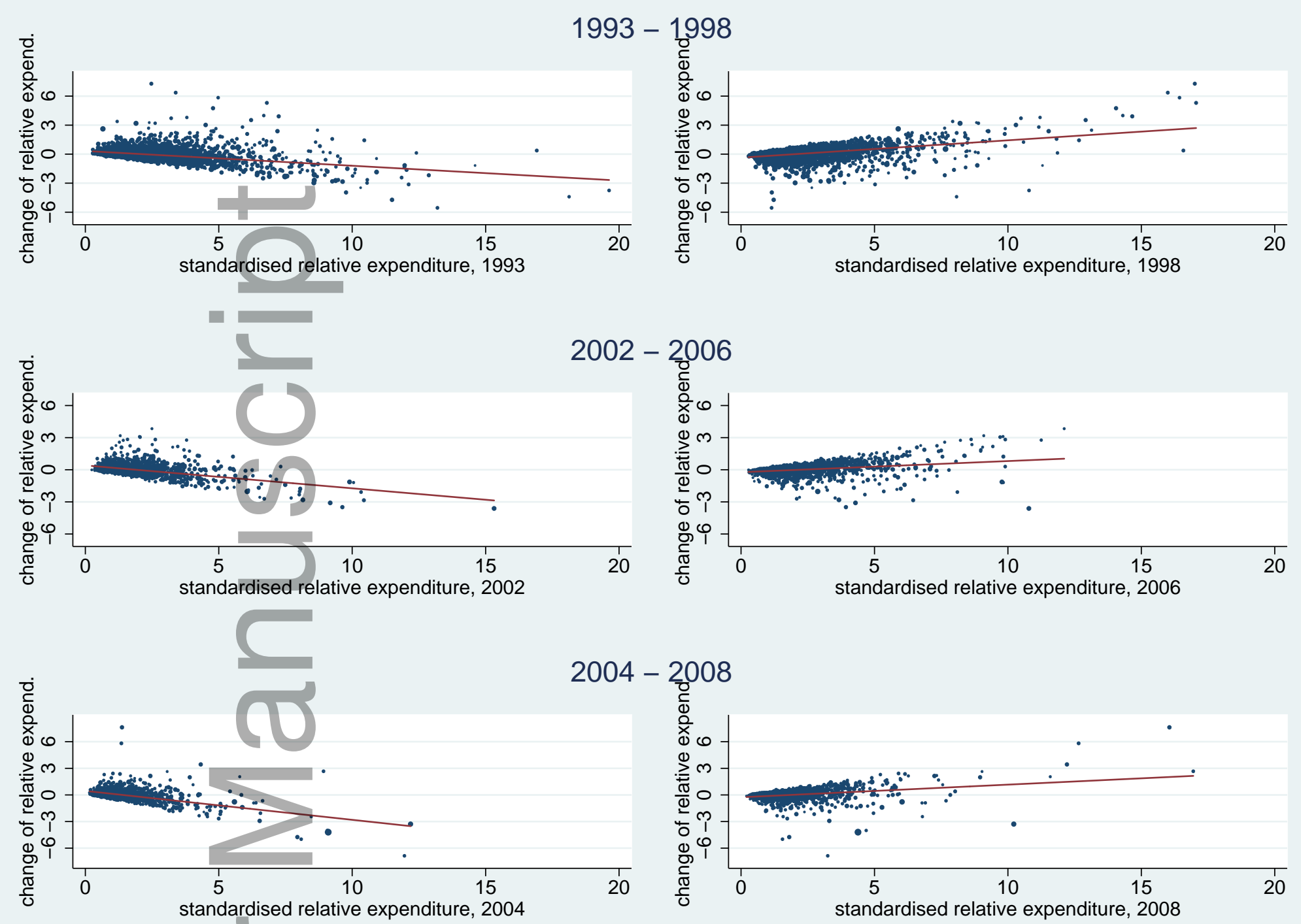

standardised relative expenditure, 2006

rode_12576_f2.eps 


\section{University Library}

\section{- M M N E R VA A gateway to Melbourne's research publications}

Minerva Access is the Institutional Repository of The University of Melbourne

Author/s:

Erreygers, G;Bui, TKT

Title:

The eye of the beholder. Reconsidering the notions of pro-poor growth and progressivity, with an application to Vietnam

Date:

2019-05-01

Citation:

Erreygers, G. \& Bui, T. K. T. (2019). The eye of the beholder. Reconsidering the notions of pro-poor growth and progressivity, with an application to Vietnam. REVIEW OF DEVELOPMENT ECONOMICS, 23 (2), pp.922-939. https://doi.org/10.1111/rode.12576.

Persistent Link:

http://hdl.handle.net/11343/284929 